\title{
Epidemiology of bronchial asthma and asthma control assessment in Henan Province, China
}

\author{
Wenping Zhang, Xianliang Chen", Lijun Ma, Jizhen Wu, Limin Zhao, Hongyan Kuang, Taibo Huang, Jianjian Cheng, \\ Luoxian Zhang, Yong Qi, Beibei Sun and Hongyan Niu
}

\begin{abstract}
Background: Prevalence of bronchial asthma, asthma treatment assessment, and estimation of the control level among asthma patients in Henan Province, China are reported in this paper.

Methods: We selected 10 among the 109 cities and districts in Henan province using a multistage stratified cluster random sampling method. A total of 500 households from each city and district were chosen. Approximately 20,000 residents from a total of 5,000 households were randomly selected to answer a questionnaire recommended by the China Asthma Alliance. Asthma patients were asked to answer a detailed questionnaire using the symptom-based guidelines to assess the levels of disease control.
\end{abstract}

Results: The overall prevalence of asthma was $0.73 \% \pm 0.12 \%$. Urban and rural residents had asthma prevalence rates of $1.1 \% \pm 0.23 \%(88 / 7,924)$ and $0.48 \% \pm 0.12 \%(57 / 11,792)$, respectively. Among the asthma patients, only $33.8 \%(52)$ received regular medication, 25\% (13) used oral glucocorticoids, and $71.1 \%$ (37) used oral theophylline. The classified control levels of patients were as follows: $33.1 \%$ controlled, $49.7 \%$ partially controlled, and $17.2 \%$ uncontrolled. A total of $38.5 \%$ and $27.5 \%$ of regularly and irregularly treated asthma patients reached controlled level, respectively. The two groups significantly differed in asthma control level.

Conclusion: Asthma prevalence is low in Henan Province, China. Urban residents have higher prevalence of asthma than rural residents do. Patients with asthma receive insufficient medication, resulting in suboptimal asthma control. Improvement in diagnosis and treatment of asthma patients is urgently needed.

Keywords: Prevalence; Socioeconomic status; Medications for asthma; Asthma control; Asthma guideline

\section{Background}

Bronchial asthma is a common chronic disease of the respiratory system that affects approximately 300 million people worldwide [1]. Current Global Initiative for Asthma (GINA) guidelines reported that the prevalence of asthma is estimated to be $1 \%$ to $18 \%$ [2]. Reports have indicated changes in the overall prevalence of asthma [3-5]. However, a firm conclusion on whether the trend is increasing or declining in a particular country for a certain period is not available [6,7]. As of this writing, few epidemiological data on national asthma prevalence have been reported in China. The Chinese population has relatively low asthma prevalence. Investigation conducted by the National Prevention and Treatment of

\footnotetext{
* Correspondence: chenx1196868@126.com

Department of Respiratory and Critical Care Medicine, People's Hospital of Henan Province, Zhengzhou University, Zhengzhou, Henan Province, China
}

Children Asthma Group in 2003, which included 430,000 children aged between 0 and 15 years old in 43 cities, reported that the prevalence of childhood asthma in the urban environment is $1.97 \%$ [8]. The estimated incidence of asthma was $1.05 \%$ in Henan Province in 2000 [9]. Time trends and regional variations in asthma prevalence are difficult to assess in China because of insufficient data [10]. GINA guidelines have been the main reference source for the national asthma guidelines, and the recommended asthma control classification is widely adopted by general practitioners and respiratory specialists in China in the assessment of disease control among asthma patients. We aim to report the prevalence of asthma among residents in Henan Province in 2010 and to evaluate the treatment and disease control among asthma patients. An assessment of the asthma disease, treatment, and control level was also conducted. 
Henan province is located at the eastern part of China $\left(31^{\circ} 23^{\prime} \mathrm{N}\right.$ to $36^{\circ} 22^{\prime} \mathrm{N}$, between $110^{\circ} 21^{\prime} \mathrm{E}$ and $\left.116^{\circ} 39^{\prime} \mathrm{E}\right)$. Henan has 19 cities and is a developing province with a population of approximately 104,890,000 in 2012 [11].

\section{Methods}

\section{Study sample}

This cross-sectional study of randomly selected residents in Henan Province was conducted from June 2010 to January 2011. The sampling unit comprised groups of people living together as families or individuals living alone. The sample size was estimated as follows: overall prevalence was $P=1.05 \%(\alpha=0.05)$ and estimated total sample size was 10,000 . The actual completed sample size was 19,878 , which included 10,275 (51.7\%) males and 9,603 (48.3\%) females.

This study used stratified multi-stage cluster random sampling method (Figure 1). Henan Province comprised 109 counties (county level city) and districts. The counties were divided into three groups according to their economic status: high-, middle-, and low-level groups [12]. Districts were divided into two groups according to economic status: high- and low-level groups [12]. Three counties (one county from each group) and two districts (one district from each group) were randomly selected. Two towns were selected in each county, and two streets were selected in each district. Two administrative

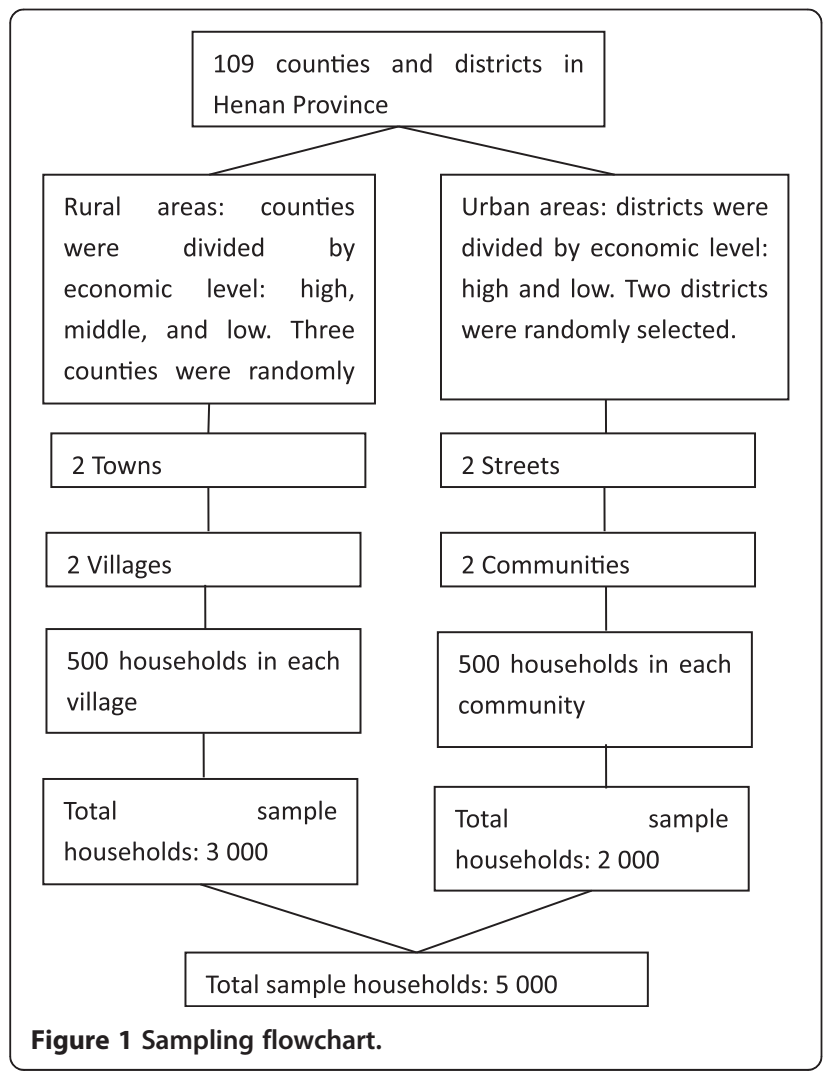

villages were selected in each township and two communities in each street. Finally, 500 household residents were randomly selected in each administrative village and community. A total of 3,000 households in rural areas and 2,000 households in urban areas were sampled. The sample was weighed to rural areas (2,000 vs. 3,000 subjects) for population in urban areas accounted for $60 \%$ of the total in Henan province. Each investigated group comprised field investigators, and survey instructors. Field investigators were trained medical interns and residents. They surveyed each household member using questionnaires. Survey instructors, who were associated chief respiratory physicians and higher-ranking medical practitioners, were responsible for organization, guidance, inspection, and quality control. We adopted the asthma questionnaire recommended by the China Asthma Alliance. The survey included general condition questions, an asthma-screening questionnaire, and a questionnaire for asthma patients. The investigation period was from April 2010 to October 2010.

\section{Asthma diagnosis}

The diagnostic criteria for bronchial asthma [13] used in both questionnaires and lung function tests included the following items. The subject should have been previously diagnosed with asthma. If the subject had no asthma history, the following 10 questions (Qs) were asked: Q1. Have you had recurrent (1) wheezing, (2) coughing, (3) breathlessness, (4) dyspnea, or (5) chest tightness more than three times?; Q2. Do you often have night or morning attacks of the symptoms in Q1?; Q3. Have you ever been awakened at night by these symptoms?; Q4. Have you ever experienced difficulty of breathing or retarded expiratory flow?; Q5. Do you hear wheezing sounds from your chest whenever these symptoms occur?; Q6. Do your symptoms resolve spontaneously?; Q7. Do your symptoms disappear after taking salbutamol or theophylline?; Q8. Do your symptoms occur or worsen during a certain season?; Q9. Do your immediate family members have asthma?; and Q10. Do your symptoms occur during or after exercise? These criteria for asthma are listed in Table 1. For suspected asthma patients, a lung function test was arranged in our hospital to establish a diagnosis. An increase in $\mathrm{FEV}_{1}$ of $\geq 12 \%$ and $\geq 200 \mathrm{ml}$ after administration of a bronchodilator indicates reversible airflow limitation consistent with asthma.

Table 1 Criteria for asthma in this study

\begin{tabular}{lllll}
\hline & Asthma & & Suspected asthma \\
\hline Q1 (1) & Yes & No & Yes & No \\
Q1 (2)-(5) & & Yes & & Yes \\
Q2-Q10 & Yes $\geq 5$ & Yes $\geq 6$ & Yes $\geq 3$, but $<5$ & Yes $\geq 4$, but $<6$ \\
\hline
\end{tabular}




\section{Asthma control}

Asthma control was assessed for 4 weeks using the asthma control classification recommended by GINA. Table 2 describes the characteristics of controlled, partially controlled, and uncontrolled asthma.

\section{Statistical analysis}

Prevalence rates with 95\% confidence intervals were estimated for all participants in each sample area and for participants in each age group. An $X^{2}$ test was used for prevalence comparison across the two groups. A $P$ value of less than 0.05 was considered statistically significant.

All data analyses were performed using SPSS version 19.0 (SPSS, Inc., Chicago, IL).

\section{Results}

\section{Prevalence of asthma}

Among the 19,861 participants in this study, $51.7 \%$ $(10,275)$ were males. Table 3 summarizes the demographic and health profiles of the sampling areas. Sex did not vary significantly, but education level, smoking habit, and medical insurance of the residents varied between the rural and urban sampling areas. A total of 145 people were diagnosed as asthma sufferers, including 79 males. The total morbidity rate was $0.73 \% \pm 0.12 \%$, and prevalence rates of male and female were $0.76 \% \pm 0.17 \%$ and $0.69 \% \pm 0.17 \%$, respectively. Table 4 lists the prevalence rates in each sampling area.

Prevalence of asthma among urban residents (Longting District of Kaifeng, Zhongyuan District of Zhengzhou) was $1.1 \% \pm 0.23 \%(88 / 7,924)$, whereas that in rural residents (high-tech zone in Puyang, Mengjin County, and Zhongmu County) was $0.48 \% \pm 0.12 \%(57 / 11,792)$. A significant difference was found for prevalence of asthma between rural and urban areas $\left(X^{2}=25.13, P<0.01\right)$. The prevalence of asthma among urban residents in areas with different economic development levels was significantly different $\left(X^{2}=5.176, P=0.02\right)$. The prevalence of asthma among rural residents in areas with different economic development levels was significantly different $\left(X^{2}=16.92\right.$, $P<0.01)$.

\section{Prevalence of asthma in different age groups}

The survey, which included 2,857 children, showed that 13 children had asthma. The prevalence of asthma in children was $0.49 \% \pm 0.26 \%$. A total of 17,004 participants were adults aged $\geq 14$ years, among which 131 had asthma. The prevalence of asthma in adults was $0.77 \% \pm 0.13 \%$. No significant difference was observed between the prevalence rate of adults and children $(P=0.10)$. Table 5 shows the prevalence of asthma in the different age groups.

\section{Medications used for treating asthma}

Among 154 patients with asthma, only 33.8\% $(n=52)$ received asthma medication regularly. Among patients who received regular treatment, $25 \%(n=13)$ used oral glucocorticoids, $71.1 \%(\mathrm{n}=37)$ used oral theophylline, 9.6\% $(\mathrm{n}=5)$ used oral leukotriene modifiers, 3.8\% (2) used oral short-acting $\beta_{2}$ receptor agonist, $5.8 \%(n=3)$ used oral long-acting $\beta_{2}$ receptor agonist, 17.3\% $(n=9)$ used glucocorticoid inhalation, $7.7 \%(\mathrm{n}=4)$ used longacting $\beta_{2}$ agonist inhalation, 7.7\% $(n=4)$ used shortacting $\beta_{2}$ receptor agonist inhalation, $1.9 \%(n=1)$ used intravenous corticosteroids, and $1.9 \%(\mathrm{n}=1)$ used intravenous glucocorticoids. Among the 52 people who received regular treatment, $32.7 \%(\mathrm{n}=17)$ used a combination of two or more kinds of medicines. The most common combination therapy was oral corticosteroids and oral theophylline ( $\mathrm{n}=7$ cases). Seven cases inhaled corticosteroids, and only two cases used medication combined with inhaled short-acting $\beta_{2}$ receptor agonist.

\section{Asthma control}

All 145 asthma patients received clinical evaluation of asthma control by symptom-based guidelines. The controlled level was achieved in 48 (33.1\%) of the patients. A total of $72(49.7 \%)$ patients achieved partially controlled level, and 25 (17.2\%) patients were classified as uncontrolled. Patients receiving regular treatment accounted for $38.5 \%(n=20)$ in the controlled group and $61.5 \%$ in the partially controlled and uncontrolled groups. Among patients without regular treatment, $27.5 \%(n=28)$ had controlled asthma and $72.5 \%$ had partially controlled and uncontrolled asthma. Patients who received medicines

Table 2 Levels of asthma control

\begin{tabular}{llll}
\hline Assessment of current clinical control (preferably over $\mathbf{4}$ weeks) & \\
\hline Characteristics & $\begin{array}{l}\text { Controlled } \\
\text { (all of the following) }\end{array}$ & $\begin{array}{l}\text { Partially controlled } \\
\text { (any measure present) }\end{array}$ & Uncontrolled \\
\hline Daytime symptoms & None (twice a week or less) & More than twice a week & Three or more features of partially controlled asthma \\
Limitation of activities & None & Any & Any \\
Nocturnal symptoms & None & None (twice a week or less) & More than twice a week \\
\hline
\end{tabular}


Table 3 Sample characteristics in Henan Province from January 2010 to June 2010

\begin{tabular}{|c|c|c|c|c|c|c|}
\hline & Urban & & Rural & & & P-value \\
\hline & $\begin{array}{l}\text { Zhongyuan district } \\
\text { in Zhengzhou } \\
\text { (economic level - H) }\end{array}$ & $\begin{array}{l}\text { Longting District in } \\
\text { Kaifeng } \\
\text { (economic level - L) }\end{array}$ & $\begin{array}{l}\text { Zhongmu county } \\
\text { (economic level - H) }\end{array}$ & $\begin{array}{l}\text { High-tech zone in } \\
\text { Puyang City } \\
\text { (economic level - L) }\end{array}$ & $\begin{array}{l}\text { Mengjin County } \\
\text { (economic level - M) }\end{array}$ & \\
\hline Subjects (n) & 4,017 & 3,907 & 4,180 & 3,894 & 3,718 & \\
\hline Females & $48.8 \%$ & $49.5 \%$ & $48.1 \%$ & $48.0 \%$ & $48.8 \%$ & 0.686 \\
\hline College degree & $4.3 \%$ & $8.8 \%$ & $0.9 \%$ & $1.2 \%$ & $1.2 \%$ & $<0.01$ \\
\hline $\begin{array}{l}\text { Without medical } \\
\text { insurance }\end{array}$ & $0.4 \%$ & $4.5 \%$ & $1.1 \%$ & $0.3 \%$ & $0.5 \%$ & $<0.01$ \\
\hline $\begin{array}{l}\text { Smoke or smoked } \\
\text { in the past }\end{array}$ & $16.2 \%$ & $21.1 \%$ & $23.1 \%$ & $22.5 \%$ & $21.1 \%$ & $<0.01$ \\
\hline
\end{tabular}

regularly and those who did not showed significant difference in asthma control.

Asthma control rate among urban residents living in Zhongyuan District of Zhengzhou and Longting District of Kaifeng City was 0.35 and 0.39, respectively. Asthma control rates among rural residents living in Zhongmu County, high-tech zone in Puyang, and Mengjin County were $0.37,0.33$, and 0.05 , respectively (Figure 2). The level of asthma control in Mengjin County was lower compared with that of the other sample areas.

Table 6 presents the characteristics of asthma sufferers according to the level of control. Among patients with partially controlled and uncontrolled asthma, untreated patients comprised a higher percentage than treated patients did $(41.93 \%$ vs. $20.77 \%, \mathrm{p}<0.01)$. Patients in urban areas showed a higher rate of controlled asthma than those in rural areas $(20.78 \%$ vs. $10.39 \%, \mathrm{p}<0.01)$.

\section{Discussion}

This cross-sectional observational study showed that the prevalence rate of asthma in Henan Province, China was $0.73 \%$, whereas a prevalence rate of $1.05 \%$ was reported in 2000 by Wang et al. [9]. The prevalence of asthma in other areas in China varied widely, with only $0.38 \%$ in Qinghai Province [14] and 0.94\% in Guangdong Province [15]. Compared with previous studies, our research focused more on the differences in asthma prevalence between urban and rural areas and prevalence in areas with different economic levels. We determined the relationship between socioeconomic status and asthma prevalence. As reported previously, asthma comprises a range of heterogeneous phenotypes that differ in presentation, etiology, and pathophysiology. The risk factors for each recognized phenotype of asthma are complex and include genetic, environmental, and host factors. In terms of social environment and lifestyle, the increase in the prevalence of asthma was suggested to be related to modern Western culture [16,17]. Chinese lifestyle is transitioning from traditional to modern more quickly and at a shorter period than in many other countries [18]. Compared with the data (prevalence rate $=1.05 \%$ ) obtained 10 years ago, the trend in the prevalence of asthma in Henan Province did not increase. This result may be related to the under-developed economy of Henan province. The province has a rural population of nearly $60 \%$ [11], and this population retains the traditional lifestyle. The role of outdoor air pollution in causing asthma remains unclear [3]. Previous studies have shown that the prevalence rate of asthma among city residents was $1.1 \%$, which was significantly higher than that in rural areas $(0.48 \%)$. Outdoor environmental pollution may be the main reason for this phenomenon. A higher concentration of harmful gas and fine particulate matter (PM2.5) is present in outdoor air in cities than in rural areas. PM2.5 is not only associated with

Table 4 Asthma prevalence in each sampling area in Henan Province from January 2010 to June 2010

\begin{tabular}{llll}
\hline Sampling area & No. of samples & Cases of asthma & Prevalence of asthma (\%) \\
\hline Urban area & 7,924 & 88 & $1.11 \pm 0.23$ \\
Zhongyuan District in Zhengzhou (economic level - H) & 4,017 & 34 & $0.846 \pm 0.28$ \\
Longting District in Kaifeng (economic level - L) & 3,907 & 54 & $1.382 \pm 0.37$ \\
Rural area & 11,792 & 57 & $0.483 \pm 0.12$ \\
Zhongmu County (economic level - H) & 4,180 & 33 & $0.789 \pm 0.27$ \\
High-tech zone in Puyang City (county) (economic level - L) & 3,894 & 6 & $0.154 \pm 0.12$ \\
Mengjin County (economic level - M) & 3,718 & 18 & $0.484 \pm 0.22$ \\
\hline
\end{tabular}

${ }^{*}$ Comparison of asthma prevalence between residents in urban and rural areas. ${ }^{* *}$ Comparison of prevalence in different urban areas. ${ }^{* * *}$ Comparison of asthma prevalence among residents in different rural areas. 
Table 5 Asthma prevalence in the different age groups

\begin{tabular}{lllll}
\hline $\begin{array}{l}\text { Age group } \\
\text { (years) }\end{array}$ & $\begin{array}{l}\text { No. of } \\
\text { samples }\end{array}$ & $\begin{array}{l}\text { Asthma } \\
\text { cases }\end{array}$ & Prevalence (\%) & P value \\
\hline Children & & & & \\
$0-13$ & 2,694 & 13 & $4.8 \pm 2.6$ & $0.10^{*}$ \\
Adults & 17,167 & 131 & $7.6 \pm 1.3$ & \\
$14-25$ & 2,982 & 13 & $4.3 \pm 1.2$ & \\
$26-45$ & 6,597 & 30 & $4.5 \pm 2.3$ & \\
$46-65$ & 5,328 & 49 & $9.2 \pm 2.5$ & \\
$66-75$ & 1,541 & 21 & $13.6 \pm 5.7$ & \\
$\geq 76$ & 719 & 19 & $26.4 \pm 11.7$ & \\
Total & 19,861 & 145 & $7.3 \pm 1.2$ & \\
\hline
\end{tabular}

*Comparison of prevalence rates between adults and children.

increasing asthma prevalence among children with related emergency and hospitalization [19], but also with adult-onset asthma [20].

In this study, we found that the prevalence of asthma in a city with a high-level economy was lower than that in a city with a low-level economy. By contrast, prevalence of asthma in a rural area with a high-level economy was higher than that in a rural area with a low-level economy. Previous studies have indicated that the prevalence of asthma is positively associated with socioeconomic status, and the incidence rate in families is negatively associated with economic condition [21,22]. However, other studies showed contradictory conclusions $[23,24]$. Given that social economic status comprises numerous factors including geographical environment, air pollution, and health habits, determining the relationship between socioeconomic status and asthma incidence is difficult $[25,26]$.

We studied the asthma control issues in rural and urban areas, including medication used and level of disease control among asthma sufferers in these areas. We found that patients receiving long-term treatment accounted for only $33.8 \%$, and that the most commonly used medications were oral glucocorticoids and theophylline. Only two in 145 patients were treated by inhaled corticosteroids combined with rapid-acting $\beta 2$ receptor agonists. These results showed that asthma management was poor. Implementation of general practitioners, specialists' consultation, and patients' education according to the guideline has been strengthened to improve the diagnosis and treatment of asthma in Henan province.

In this study, we used symptom-based guidelines to assess the disease control level of asthma patients. The patient classifications according to the symptom-based guidelines were as follows: controlled, $33.1 \%$; partially controlled, 49.7\%; and uncontrolled, $17.2 \%$. Partially controlled and uncontrolled rates accounted for $66.9 \%$. In Canada, asthma control was administered to $\sim 53 \%$ of adults in the age range of 18 years old to 54 years old who reported having this disease; asthma control was assessed using symptom-based guidelines [27]. In eight European countries and in Canada, Australia, and the USA, the rate of uncontrolled asthma was 51\%; asthma control was assessed using the Asthma Control Questionnaire [28].

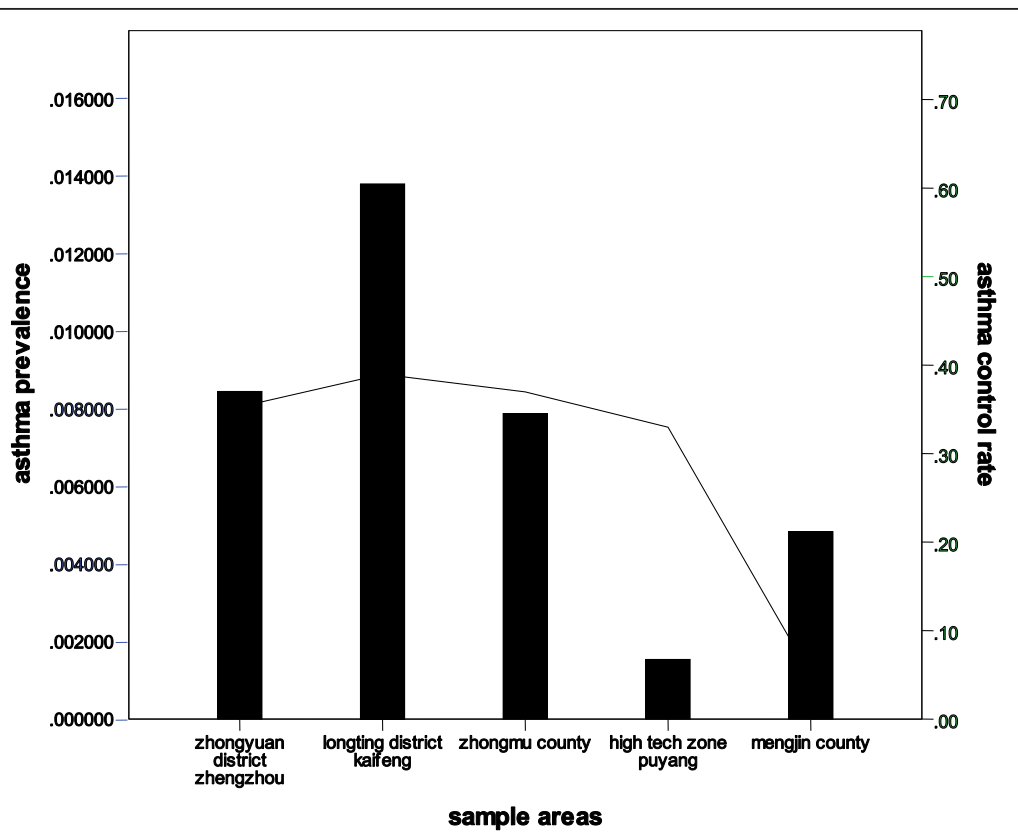

Figure 2 The bars show asthma prevalence, and the curve shows asthma control rate in the sampling areas. Asthma control rate was computed as the ratio of controlled to partially controlled and uncontrolled asthma sufferers. 
Table 6 Characteristics of asthma sufferers by control classification

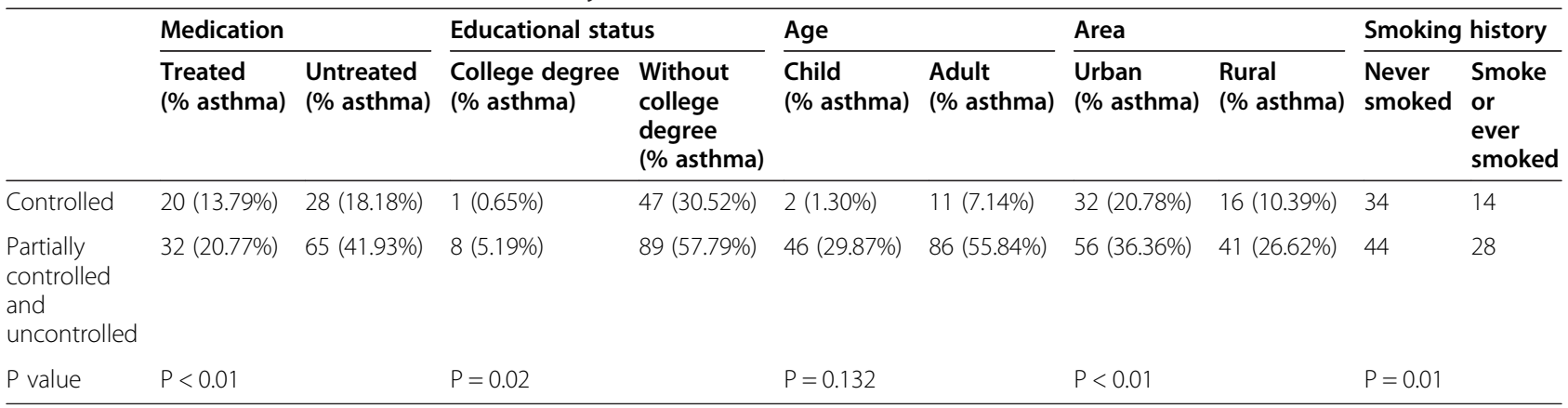

In France, Germany, Italy, Spain, and the UK, the uncontrolled rate was $\sim 50 \%$, and asthma control was assessed with the Asthma Control Test [29]. In Henan Province, insufficient management of asthma may be among the reasons for poor asthma control.

In this study, asthma patients were divided into two groups according to control level (Table 6) to determine the differences between the controlled group and the uncontrolled and partially controlled groups. By comparing age, education level, smoking history, regular treatment, and living area, we found that a higher proportion of urban residents and a larger number of sufferers receive regular treatment in the controlled group than in the partially controlled and uncontrolled groups. This finding indicates that urban residents may have access to better treatments than rural residents, and the disease control rate may be higher in urban areas than in rural areas.

This study has limitations and potential biases. Data are limited to one province of China, and these data may not represent the situation in the other Chinese provinces that are geologically different from Henan. The prevalence may also be underestimated because the diagnoses of some patients may have been based on selfreported data or the criteria for asthma may have been overestimated, leading to false positives and false negatives. However, the prevalence results obtained in this study were consistent with those obtained in another study [9]. Biases also exist in asthma control assessment because three children aged below five years old were included in this study and the asthma control questionnaires were completed by their parents.

\section{Conclusion}

The study showed that the prevalence of asthma in Henan Province, China was very low. Prevalence of asthma among urban residents was higher than among rural residents. Differences in asthma prevalence were also observed among urban and rural residents living in areas with different economic development levels. Treatment for asthma was insufficient in both urban and rural areas, resulting in suboptimal asthma control results.
Future studies should focus on educating primary care physicians and specialists on the importance of asthma control and implementation of the GINA guidelines.

\section{Consent}

Written informed consent was obtained from the patient for the publication of this report and any accompanying images.

\section{Competing interests}

We declare that we have no competing interests.

\section{Authors' contributions}

Conception and design: XC, LM, JW, LZ. Survey constructors: HK, TH, JC, LZ, YQ, BS, HN. Data anlysis: WZ. Drafting the manuscript for important intellectual content: WZ, XC, LM, LZ. All authors read and approved the final manuscript.

\section{Acknowledgements}

This work was supported by People's Hospital of Henan Province, Zhengzhou University.

Received: 15 November 2013 Accepted: 26 February 2014 Published: 5 March 2014

\section{References}

1. Masoli M, Fabian D, Holt S, Beasley R, Global Initiative for Asthma (GINA) Program: The global burden of asthma: executive summary of the GINA dissemination committee report. Allergy 2004, 59:469-478.

2. Global Initiative for Asthma: Global strategy for asthma management and prevention, Revised 2012. http://www.ginaasthma.com.

3. Eder W, Ege MJ, von Mutius E: The asthma epidemic. N Engl J Med 2006, 355:2226-2235.

4. Anandan C, Nurmatov U, van Schayck OCP, Sheikh A: Is the prevalence of asthma declining? Systemic review of epidemiological studies. Allergy 2010, 65:152-167.

5. Centers for Disease Control and Prevention (CDC): Vtial signs: asthma prevalence, disease characteristics, and self-management eduction United States, 2001-2009. MMWR 2011, 60(17)547-552.

6. Anderson HR, Gupta R, Strachan D, Limb E: 50 years of asthma: UK trends from 1955 to 2004. Thorax 2007, 62:85-90.

7. Simpson CR, Sheikh A: Trends in the epidemiology of asthma in England: a national study of 333,294 patients. J R Soc Med 2010, 103:98-106.

8. National Cooperation Group on Childhood Asthma(NCGCA): A national wide survey in China on prevalenceof asthma inurban children. (Article in Chinese). Chin J Pediatr 2003, 41:123-127.

9. Wang GB, Peng YL, Du CH, Tang BX, Liu JG, Zhen XA, Wang CH, Xing J, Xu JY, Wang GJ, Jiao XF: Prevalence and epidemilogic characters of asthma in Henan Province (Article in Chinese). Chin J Tuberc Respir Dis 2002, 25:25-28.

10. Yangzong Y, Shi Z, Nafstad P, Håheim LL, Luobu O, Bjertness E: The prevalence of childhood asthma in China: a systematic review. BMC Public Health 2012, 12:860 
11. The People's Goverment of Henan province: Introduction of Henan Province. http://www.henan.gov.cn/hngk/.

12. Wang XD: Research on the economical development of Henan Province of China by PCA (principal components analysis). (Article in Chinese). J Anyang Inst Technol 2012, 11(3):42-44.

13. Branch of Chinese Medical Association for Respiratory Diseases (BCMARD): Bronchial asthma therapeutic guidelines (definition, diagnosis, treatment of bronchial asthma). (Article in Chinese). Chin J Tuberc Respir Dis 2008, 31(3):177-185

14. Gao F, Yang QJ, Zhang HG: Prevalence and epidemilogic characters of asthma in Qinhai Province (Article in Chinese). Chin J Tuberc Respir Dis 2011, 34(3):165-168.

15. Tang TQ, Ding Y, Zheng JP, Wang XP, Ma QF, Liang B, Chen SW, Cai DM: Prevalence and epidemilogic characters of asthma in Guangdong Province (Article in Chinese). Chin J Tuberc Respir Dis 2000, 23(12):730-733.

16. Beasley R, Crane J, Lai CK, Pearce N: Prevalence and etiology of asthma. Allery Clin Immuol 2000, 105:\$466-\$472.

17. Britton J: Parasite, allergy, and asthma. Am J Respir Crit Care Med 2003, 168:266-267.

18. Yang G, Kong L, Zhao W, Wan X, Zhai Y, Chen C, Koplan JP: Emergence of chronic non-communicable diseases in China. Lancet 2008, 372:1697-1705.

19. American Thorax Society: What constitutes an adverse health effect of air pollution? Offical statement of the American thorax society. Am J Respir Crit Care Med 2000, 161(2pt 1):665-673.

20. Künzli N, Bridevaux PO, Liu LJ, Garcia-Esteban R, Schindler C, Gerbase MW, Sunyer J, Keidel D, Rochat T: Swiss cohort study on Air pollution and lung diseases in adults:traffic-related air pollution correlates with adult-onset asthma among never-smokers. Thorax 2009, 64:664-670

21. Farfel A, Tirosh A, Derazne E, Garty BZ, Afek A: Association between socioeconomic status and the prevalence of asthma. Ann Allergy Asthma Immunol 2010, 104(6):490-495.

22. Kozyrskyj AL, Kendall GE, Jacoby P, Sly PD, Zubrick SR: Association between socioeconomic status and the development of asthma: analyses of income trajectories. Am J Public Health 2010, 100(3):540-546.

23. Ellison-Loschmann L, Sunyer J, Plana E, Pearce N, Zock JP, Jarvis D, Janson C, Antó JM, Kogevinas M: European community respiratory health survey: socioeconomic status, asthma and chronic bronchitis in a large community-based study. Eur Respir J 2007, 29(5):897-905.

24. Almqvist C, Pershagen G, Wickman M: Low socioeconomic status as a risk factor for asthma, rhinitis and sensitization at 4 years in a birth cohort. Clin Exp Allergy 2005, 35(5):612-618.

25. Wright RJ, Subramanian SV: Advancing a multilevel framework for epidemiologic research on asthma disparities. Chest 2007, 132(5 Suppl):757S-769S.

26. Hancox RJ, Milne BJ, Taylor DR, Greene JM, Cowan JO, Flannery EM, Herbison GP, McLachlan CR, Poulton R, Sears MR: Relationship between socioeconomic status and asthma: a longitudinal cohort study. Thorax 2004, 59(5):376-380

27. FitzGerald JM, Boulet LP, Mclvor RA, Zimmerman S, Chapman KR: Asthma control in Canada remains suboptimal: The Reality of Asthma Control (TRAC) study. Can Respir J 2006, 13:253-259.

28. Partridge MR, van der Molen T, Myrseth SE, Busse WW: Attitudes and actions of asthma patients on regular maintence therapy: The INPIRE study. BMC Pulm Med 2006, 6:13.

29. Demoly P, Paggiaro P, Plaza V, Bolge SC, Kannan H, Sohier B, Adamek L: Prevalence of asthma control among adults in France, Germany, Italy, Spain and the UK. Eur Respir Rev 2009, 18(112):105-112.

doi:10.1186/2213-0802-2-5

Cite this article as: Zhang et al: Epidemiology of bronchial asthma and asthma control assessment in Henan Province, China. Translational

Respiratory Medicine 2014 2:5.

\section{Submit your manuscript to a SpringerOpen ${ }^{\circ}$ journal and benefit from:}

- Convenient online submission

- Rigorous peer review

- Immediate publication on acceptance

- Open access: articles freely available online

- High visibility within the field

- Retaining the copyright to your article

Submit your next manuscript at $>$ springeropen.com 